\title{
Triblock Copolymer Nanomicelles Loaded with Curcumin Attenuates Inflammation via Inhibiting the NF-KB Pathway in the Rat Model of Cerebral Ischemia
}

\author{
Fengguang $\mathrm{Li}^{1, *}$ \\ Yan $\mathrm{Xu}^{2, *}$ \\ Xing $\mathrm{Li}^{\mathrm{I}}$ \\ Xinghua Wang' \\ Zhigang Yang' \\ Wanli $\mathrm{Li}^{\prime}$ \\ Wei Cheng' \\ Gangli Yan'
}

'Department of Neurology, Puren Hospital Affiliated to Wuhan University of Science and Technology, Wuhan, 43008I, People's Republic of China ${ }^{2}$ Department of Pharmacy, General Hospital of Central Theater Command, Wuhan, 430010, People's Republic of China

*These authors contributed equally to this work
Correspondence: Gangli Yan

No. I Benxi Street, Qingshan District, Wuhan, 43008I, Hubei Province, People's Republic of China

Email gangli_yan@I26.com

\begin{abstract}
Aim: Cerebral ischemic injury is one of the debilitating diseases showing that inflammation plays an important role in worsening ischemic damage. Therefore, studying the effects of some potential anti-inflammatory compounds can be very important in the treatment of cerebral ischemic injury.

Methods: This study investigated anti-inflammatory effects of triblock copolymer nanomicelles loaded with curcumin (abbreviated as NC) in the brain of rats following transient cerebral ischemia/reperfusion (I/R) injury in stroke. After preparation of $\mathrm{NC}$, their protective effects against bilateral common carotid artery occlusion (BCCAO) were explored by different techniques. Concentrations of free curcumin (C) and NC in liver, kidney, brain, and heart organs, as well as in plasma, were measured using a spectrofluorometer. Western blot analysis was then used to measure NF- $\mathrm{B}$-p65 protein expression levels. Also, ELISA assay was used to examine the level of cytokines IL-1 $\beta$, IL-6, and TNF- $\alpha$. Lipid peroxidation levels were assessed using MDA assay and H\&E staining was used for histopathological examination of the hippocampus tissue sections.
\end{abstract}

Results: The results showed a higher level of $\mathrm{NC}$ compared to $\mathrm{C}$ in plasma and organs including the brain, heart, and kidneys. Significant upregulation of NF- $\mathrm{B}$, IL-1 $\beta$, IL-6, and TNF- $\alpha$ expressions compared to control was observed in rats after induction of $I / R$, which leads to an increase in inflammation. However, $\mathrm{NC}$ was able to downregulate significantly the level of these inflammatory cytokines compared to C. Also, the level of lipid peroxidation in pre-treated rats with $80 \mathrm{mg} / \mathrm{kg} \mathrm{NC}$ was significantly reduced.

Conclusion: Our findings in the current study demonstrate a therapeutic effect of NC in an animal model of cerebral ischemia/reperfusion (I/R) injury in stroke through the downregulation of NF-kB-p65 protein and inflammatory cytokines.

Keywords: ischemia-reperfusion injury, stroke, NF-kB, inflammation, curcumin, nanomicelle, rat

\section{Introduction}

Stroke is currently the second leading cause of death and long-term disability in developed countries and its trend is on the rise. ${ }^{1,2}$ About $85 \%$ of strokes are caused by ischemia, which results from thrombosis, embolism, and decreased systemic blood flow. ${ }^{3}$ Delayed improvement in blood flow due to the activation of the oxidative stress process causes greater damage than the initial damage, which leads to endothelial dysfunction, capillary obstruction, damage to tissue and oxygen 
supply, followed by blood-brain barrier disruption, and cerebral edema. ${ }^{4}$ At present, despite the significant information available in stroke prevention, there are fewer options for treatment, and the gold standard for the treatment of stroke is intravenous recombinant tissue plasminogen activator (IV r-TPA), which can restore brain function only up to about 4 to $5 \mathrm{hrs}$ after stroke. Therefore, it can be used only in $2-4 \%$ of patients with stroke. ${ }^{5}$ It is very important to restore blood flow in I/ R-affected areas of the brain by thrombolysis, which causes the clots to dissolve rapidly. ${ }^{6}$ Although this type of treatment reduces the apoptosis of neuronal cells, it induces inflammatory responses that lead to oxidative and inflammatory damage. ${ }^{7}$ Therefore, finding novel treatment strategies to reduce this type of oxidative and inflammatory damage in cerebral $\mathrm{I} / \mathrm{R}$ conditions is very important. ${ }^{8}$

Therefore, the aim of the current study was to investigate the protective effects of $\mathrm{NC}$ on brain damage induced by cerebral $\mathrm{I} / \mathrm{R}$ injury as well as its effects on the inflammatory response of the NF- $\mathrm{KB}$ pathway.

\section{Materials and Methods}

\section{Preparation of C-Loaded Nanomicelles}

PLA-PEG-PLA, PLA average Mn 1500, PEG average Mn 900, average $\mathrm{Mn} \sim 2000$ was purchased from Sigma Co. (USA). The PLA-PEG-PLA polymers precipitated above $60 \mathrm{mg} / \mathrm{mL}$; therefore, we prepared samples of $50 \mathrm{mg} / \mathrm{mL}$, which is also above the critical micelle concentration (CMC). The preparation of C-loaded nanomicelles was done based on using the thin film hydration method. ${ }^{26}$ Briefly, stock solutions of PLA-PEG-PLA (50 mg/mL) and curcumin $(10 \mathrm{mg} / \mathrm{mL})$ in ethanol were prepared. These solutions were then transferred into vials and ethanol was subsequently evaporated employing a heat gun. Afterward, the vials were dried at $50{ }^{\circ} \mathrm{C}$ in a vacuum oven and the formed layers were rehydrated with distilled water and used for further characterization techniques. The obtained solutions were vortexed for $2 \mathrm{~min}$, centrifuged (2500 rpm for $15 \mathrm{~min}$ ), and the supernatant was utilized in further experiments.

\section{Characterization of NCs}

The diameter of nanomicelles was evaluated by transmission electron microscopy (TEM, Electron Microscopy Sciences, Hatfield, PA, USA). The size and zeta potential of nanomicelles and NC were determined using Zetasizer
Nano ZS (model ZEN 3600; Malvern Instruments, Inc., Malvern, UK) at room temperature.

\section{Analysis of Curcumin Loading}

To measure encapsulation efficiency (EE) of $\mathrm{C}$ in nano micelles, the $\mathrm{NC}$ was resuspended in distilled water to have a final concentration of $10 \mathrm{mg} / \mathrm{mL}$ of a PLA-PEGPLA and $2 \mathrm{mg} / \mathrm{mL}$ of curcumin. The solution was further centrifuged ( $2500 \mathrm{rpm}$ for $15 \mathrm{~min}$ ) and $50 \mu \mathrm{L}$ of the final solution was added by $450 \mu \mathrm{L}$ of ethanol and measured by UV-vis spectrophotometry at $\lambda_{\max }$ of $420 \mathrm{~nm}$ using the following equation:

$$
\mathrm{EE} \%=\frac{\text { total amount of } \mathrm{C}-\text { free amount of } \mathrm{C}}{\text { total amount of } \mathrm{C}} \times 100
$$

\section{Curcumin Release in vitro}

After NC preparation and centrifugation, the supernatants of rehydrated samples were transferred into dialysis bags (MINI Dialysis Units, 3.5 cut-off MWCO). The bags were then placed in a medium containing $2 \mathrm{~mL}$ of $\mathrm{PBS}(\mathrm{pH}$ : 7.4). Then, $50 \mu \mathrm{L}$ of the medium was removed and the same amount was replaced by PBS to ensure the sink condition. Finally, the $\mathrm{C}$ release from $\mathrm{NC}$ was quantified by $U V$-vis spectrophotometry at $\lambda_{\max }$ of $420 \mathrm{~nm}$.

\section{Experimental Protocols and Groups}

Forty-eight adult male Wistar rats, weighing 200-220g (aged 4-5 weeks), were prepared by the neurology department, Wuhan University of Science and Technology, China. The study protocol was approved by the Institutional Animal Care Committee at Wuhan University. All animals were kept in standard laboratory conditions (temperature: $24^{\circ} \mathrm{C} \pm 1{ }^{\circ} \mathrm{C}$, humidity: $55 \% \pm 10 \%$, lighting: 12-h light/dark cycle), and they had access to food and water freely all the time during this study (Animal Welfare Regulations (USDA 1985; US Code, 42 USC $§ 289 d)$ ).

The rats were randomly divided into 6 groups, as follows:

1. The control group received normal saline solution.

2. The stroke group received normal saline solution.

3 . The stroke group received nanomicelles.

4. The stroke group received curcumin $80 \mathrm{mg} / \mathrm{kg}$ $(\mathrm{C} 80 \mathrm{mg} / \mathrm{kg})$ dissolved in drinking water. 
5. The stroke group received triblock copolymer nanomicelles loaded with curcumin $80 \mathrm{mg} / \mathrm{kg}$ (NC80 $\mathrm{mg} / \mathrm{kg}$ ).

6. The stroke group received triblock copolymer nanomicelles loaded with curcumin $40 \mathrm{mg} / \mathrm{kg}$ (NC40mg $/ \mathrm{kg}$ ).

Groups 3-6 were treated orally through gavage with nanomicelles, $\mathrm{C}$ and $\mathrm{NC}$ for 14 days; $24 \mathrm{~h}$ after the last gavage, the stroke was induced.

\section{Plasma and Tissue Distribution of NC}

After administration of the last dose of $\mathrm{C}$ or $\mathrm{NC}$ in the studied rats, blood samples were taken by heart puncture at $1,2,4,8,16,24,48$, and $72 \mathrm{~h}$ to measure the plasma concentrations of $\mathrm{C}$ and $\mathrm{NC}$. After centrifugation at $3000 \mathrm{rpm}$ for $10 \mathrm{~min}$, plasma $\mathrm{C}$ and $\mathrm{NC}$ concentrations were determined by spectrofluorometry with excitation and emission wavelengths of 485 and $590 \mathrm{~nm}$, respectively.

Concentrations of $\mathrm{C}$ and $\mathrm{NC}$ in the liver, kidneys, brain, and heart were also measured. For this purpose, the rats were killed $24 \mathrm{~h}$ after the last dose of $\mathrm{C}$ and $\mathrm{NC}$ administration and the organs were isolated and washed with PBS and then lysed and homogenized. The tissue homogenate was treated with acidified isopropanol to extract $\mathrm{C}$ and $\mathrm{NC}$ and, after centrifugation, the supernatant was analyzed by spectrofluorometer.

\section{BCCAO Induction}

For inducing stroke by bilateral common carotid artery occlusion (BCCAO), rats were anesthetized by injection of ketamine $(50 \mathrm{mg} / \mathrm{kg})$ and xylazine $(2-8 \mathrm{mg} / \mathrm{kg})$ intraperitoneally (i.p). Then, the animals' tails and paws were fixed using adhesive tape. Sagittal incisions were made through the neck midline ( $1 \mathrm{~cm}$ length), then the bilateral common carotid arteries were revealed, and both carotid arteries were carefully separated from the respective vagal nerve. Avoiding any manipulation of the vagal nerve was crucial. A 5-0 silk suture loop was made around each common carotid artery. Both common carotid arteries were occluded for 30 min by tightening the silk sutures. Then, a 72-h reperfusion period was initiated. Afterward, the wounds were sutured. Finally, the rats were returned to their cages and brain sample collection based on ethical protocols and biochemical assays (ELISA kit-sigma Aldrich) were done after $72 \mathrm{~h}$.

\section{Western Blot Analysis}

Brain tissue isolated from rats, after rinsing with a cold PBS buffer, was crushed and homogenized in a microtubule with $1 \mathrm{~mL}$ RIPA (radioimmunoprecipitation assay) buffer (Abcam, Cambridge, UK) and in 1\% protease inhibitor (Sigma) in a homogenizer device. After centrifugation at $13,000 \mathrm{rpm}$ for $15 \mathrm{~min}$, the supernatant was collected and the protein concentration was determined using a BCA kit (Thermo, Pierce, USA). 60 $\mathrm{gg}$ total protein was electrophoresed on $10 \%$ polyacrylamide gel at a constant voltage of $80 \mathrm{~V}$ for $35 \mathrm{~min}$ and then $120 \mathrm{~V}$ for $45 \mathrm{~min}$. The electrophoresed proteins were then transferred to polyvinylidene fluoride (PVDF) paper and incubated with NF-кB-p65 (Cell Signaling, USA) and beta-actin ( $\beta$-actin) monoclonal antibodies at $4{ }^{\circ} \mathrm{C}$ overnight. PBST solution containing $0.1 \%$ Tween-20 was used to wash the membrane and then HRP-Rabbit antirat secondary antibody $(1: 10,000)$ against the primary antibody was incubated on the shaker for $190 \mathrm{~min}$ and then washed again. Finally, by adding chemiluminescence ECL (GE Healthcare, Uppsala, Sweden) to the PVDF paper, the presence of NF-кB-p65 protein in the samples was investigated. In addition to the samples, the negative control sample (without primary antibodies) was also electrophoresed with the same concentration of proteins. Western blot test results were analyzed using Image-Pro Plus 6.0 software (Media Cybernetics, Bethesda, MD, USA).

\section{Enzyme-Linked Immunosorbent Assay (ELISA)}

The rats were killed under deep anesthesia, then their brains were removed and stored at $-80^{\circ} \mathrm{C}$ for biochemical assays. The animals' brains were homogenized in a buffer (TRIS HCL, SDS, DTT, NP40, and glycerol), and centrifuged for 5 min. ELISA kits (Siemens AG, Siemensdamm, Germany) were used to evaluate the levels of TNF- $\alpha$, IL$1 \beta$, and IL- 6 cytokine in the rat brain tissue samples.

\section{MDA Assay}

The Rao et al method was used to measure the amount of $\mathrm{MDA}^{27}$ by thiobarbituric acid (TBA). For this purpose, rat brain tissue samples were first centrifuged at $2000 \mathrm{~g}$ for $5 \mathrm{~min}$. Then, $100 \mu \mathrm{L}$ of the supernatant along with $900 \mu \mathrm{L}$ of distilled water was added to the test tube and $500 \mu \mathrm{L}$ of TBA reagent was placed in a boiling water bath for $60 \mathrm{~min}$, after which the tubes were centrifuged again at $4000 \mathrm{~g}$ for $10 \mathrm{~min}$. Finally, the adsorption of the supernatant was read at $534 \mathrm{~nm}$ using a spectrophotometer (UV1600). 


\section{Histopathological Assay}

After separation, rat hippocampus tissue was fixed in 10\% formaldehyde solution for $24 \mathrm{~h}$ and then embedded in paraffin and cut into $5 \mu$ sections by a microtome. Sections from the CA1 and DG areas of the hippocampus were taken to examine for possible changes in brain tissue. Five tissue sections for each group were randomly examined. The sections were stained with H\&E and then examined by a light microscope (Nikon, USA) with $\times 400$ magnification.

\section{Statistical Analysis}

Data analysis was carried out using GraphPad Prism 7 software. The normal distribution of data was confirmed using the Kolmogorov-Smirnov test. Then, all data were analyzed using one-way analysis of variance (ANOVA) and the Tukey post hoc test. Data were presented as Mean \pm SEM. A probability level of $p<0.05$ was considered to be a significant difference.

\section{Results}

\section{Characterization of Nanomicelles}

The calculated DL and EE were shown to be $41.2 \%$ and $91.5 \%$, respectively. The final concentration of $\mathrm{C}$ loading in nanomicelles in the dried-powder was shown to be $2.09 \mu \mathrm{g} /$ $\mathrm{mg}$. The characterization of prepared $\mathrm{NC}$ was done by TEM and DLS techniques. As shown in Figure 1A, TEM analysis showed that prepared $\mathrm{NC}$ had a size of around $10 \mathrm{~nm}$. They were also well-dispersed and had a homogenous distribution in the sample (Figure 1A). DLS study was also done to determine the hydrodynamic radius and colloidal stability of prepared nanomicelles in the absence and presence of C. It was shown that the nanomicelles had a hydrodynamic radius of $96.67 \pm 11.94 \mathrm{~nm}$ (PDI: 0.167) with good colloidal solubility (Figure 1B). It was also observed that the loading of $\mathrm{C}$ into the nanomicelles and preparation of $\mathrm{NC}$ did not change its hydrodynamic radius (data not shown). The zeta potential of $\mathrm{C}$, nanomicelles, and $\mathrm{NC}$ was evaluated to be around $-13,54 \mathrm{mV},-12.67 \mathrm{mV}$, and $-23.52 \mathrm{mV}$, indicating
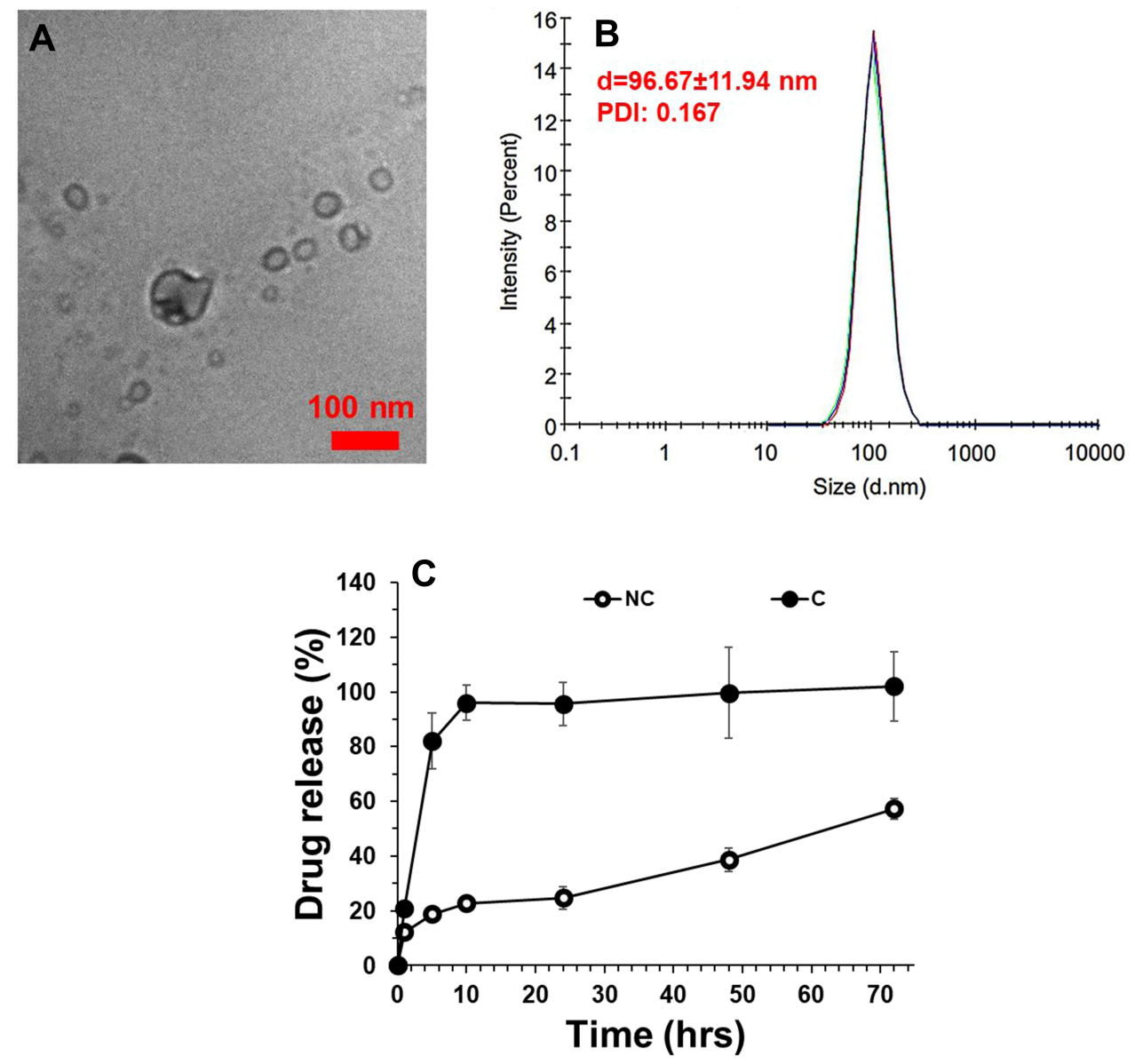

Figure I Characterizations of prepared PLA-PEG-PLA triblock copolymer NC by transmission electron microscopy (TEM) at room temperature (A) and DLS at a constant angle of 90 degrees and temperature of $25^{\circ} \mathrm{C}(\mathbf{B})$. Drug release assay of $\mathrm{C}$ from NCs at $\mathrm{pH} 7.4(\mathbf{C})(n=6)$. 
also the potential colloidal stability of NC. A drug release assay was done to evaluate the amount of $\mathrm{C}$ released into the PBS medium over time (72 h). As shown in Figure $1 \mathrm{C}$, it was indicated that $\mathrm{C}$ was gradually released from nanomicelles over $72 \mathrm{~h}$ at $\mathrm{pH}$ 7.4. Indeed, the release of $\mathrm{C}$ from nanomicelles showed slower release behavior than free C. Thus, the PLA-PEG-PLA triblock copolymer nanomicelles could improve the sustained release of $\mathrm{C}$ as a potential drug delivery system.

\section{Plasma Concentration and Tissue Distribution of $\mathrm{NC}$ in vivo}

In the rats that received $\mathrm{NC}$ and $\mathrm{C}$ orally for 14 days, the plasma concentration of $\mathrm{NC}$ was higher than free $\mathrm{C}$ and remained high for up to $24 \mathrm{~h}$ after the last administration. However, after $72 \mathrm{~h}$, complete clearance of $\mathrm{C}$ from rat plasma was observed (Figure 2A).

In the rats that received $\mathrm{NC}$ and $\mathrm{C}$ orally for 14 days, differences in $\mathrm{NC}$ and $\mathrm{C}$ content were observed in different organs such as the heart, liver, brain, and kidneys. NC content in the brain was higher than $\mathrm{C}$ and $\mathrm{NC}$ uptake in organs such as the heart, brain, and kidneys was significantly different from $\mathrm{C}$ uptake $(\mathrm{p}<0.05)$. However, no difference in $\mathrm{NC}$ and $\mathrm{C}$ uptake was observed in the liver. It appears that the nanomicelle formulation of $\mathrm{C}$ leads to the high absorption of $\mathrm{C}$ in the organs of the brain, kidneys, and heart (Figure 2B).

\section{Effects of NC on Inflammatory Cytokines in Ischemic Brains}

The results showed a nearly twofold upregulation of TNF- $\alpha$ protein level in I/R rats compared to controls, indicating an increase of inflammation in brain tissue of rats with cerebral
$\mathrm{I} / \mathrm{R}$ injury in stroke. However, $\mathrm{NC}$ in a dose-dependent manner was able to downregulate the TNF- $\alpha$ level, indicating the anti-inflammatory effects of $\mathrm{NC}$ in cerebral $\mathrm{I} / \mathrm{R}$ conditions. In the present study, $80 \mathrm{mg} / \mathrm{kg} \mathrm{NC}$ had the highest effect on downregulation of TNF- $\alpha$ level and this effect was greater compared to $80 \mathrm{mg} / \mathrm{kg}$ free $\mathrm{C}$ (Figure $3 \mathrm{~A}$ ). After induction of cerebral ischemia in rats, the IL-1 $\beta$ content increased in the stroke group compared to controls; however, as shown in Figure 3B, NC and $\mathrm{C}$ were able to reduce IL-1 $\beta$ levels. The IL-1 $\beta$ inhibitory effect of $\mathrm{C}$ and $\mathrm{NC}$ was compared and the results showed a concentration-dependent IL$1 \beta$ inhibition effect by NC. It seems that NC at a dose of $80 \mathrm{mg} / \mathrm{kg}$ was able to significantly reduce the level of IL- $1 \beta$, which indicates the anti-inflammatory effects of $80 \mathrm{mg} / \mathrm{kg}$ $\mathrm{NC}$ in conditions of cerebral I/R damage.

A sharp increase in IL-6 level was observed in the ischemia brain tissue of rats, indicating a severe inflammatory response to cerebral I/R injury in stroke. Also, the IL-6 inhibitory effect of $\mathrm{NC}$ and $\mathrm{C}$ was compared and the results showed a dose-dependent inhibitory effect of NC on downregulation of IL- 6 level so that the $80 \mathrm{mg} / \mathrm{kg}$ resulted in the lowest IL-6 content in the brain of cerebral ischemic rats. Therefore, NC formulation plays an important role in downregulating IL-6 level and shows that this formulation can reduce inflammation caused by stroke (Figure 3C).

\section{Anti-Inflammatory Effects of NC May Be Mediated Through PNF-KB Protein Downregulation}

Western blotting was used to evaluate whether the antiinflammatory effects of $\mathrm{NC}$ are related to NF-KB antagonizing. An upregulation in NF-KB protein expression was
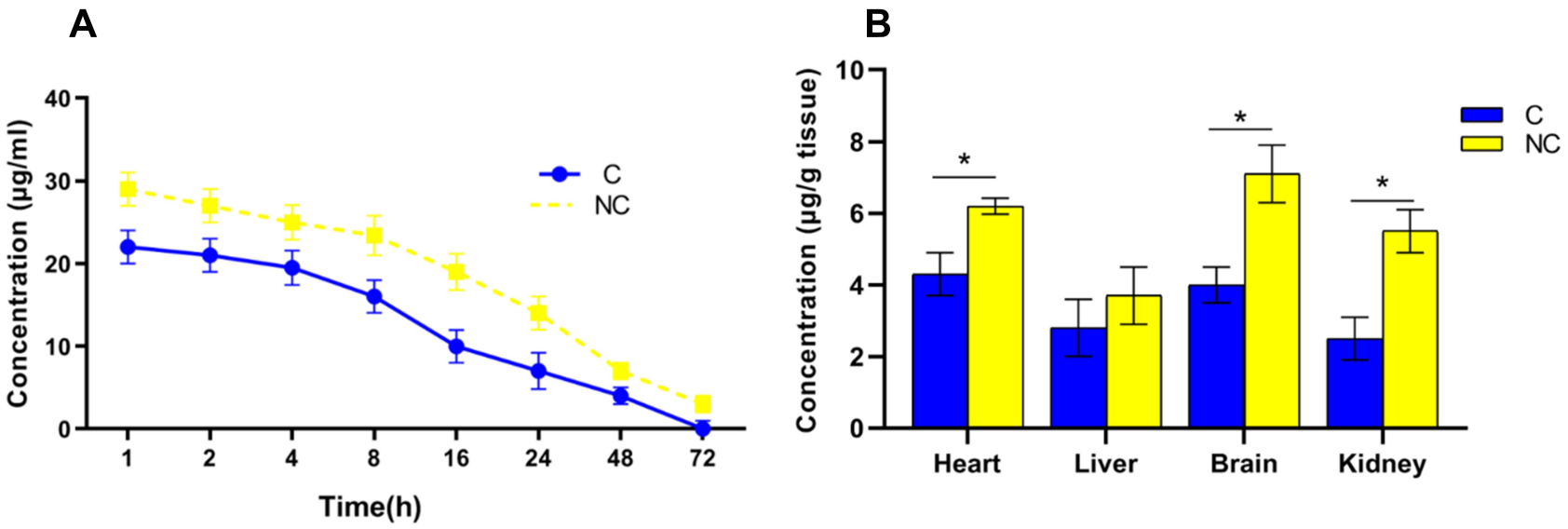

Figure 2 (A)Plasma concentrations-time curve of $C$ and NC; (B) Tissue distribution of $C$ and NC (*p $<0.05)$ after 14 days' administration of $C$ or NC by gavage ( $n=6$ ). *Indicates significant differences at probability level of $p<0.05$. 
A

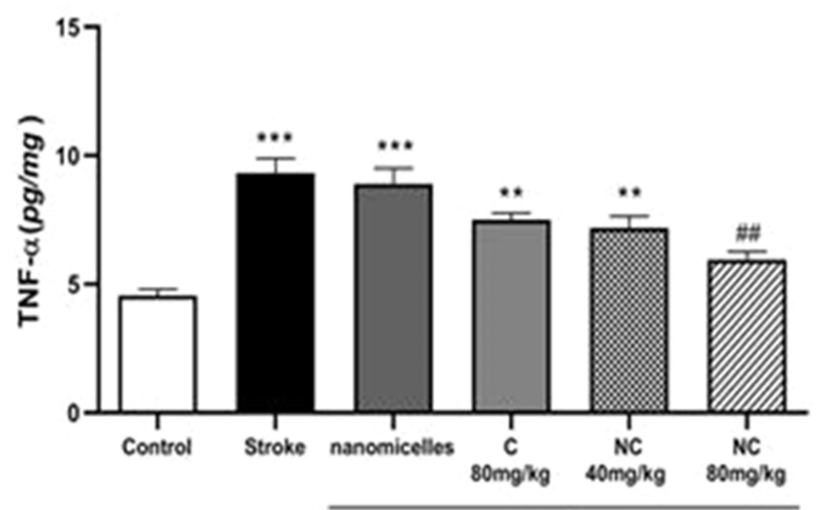

stroke
B

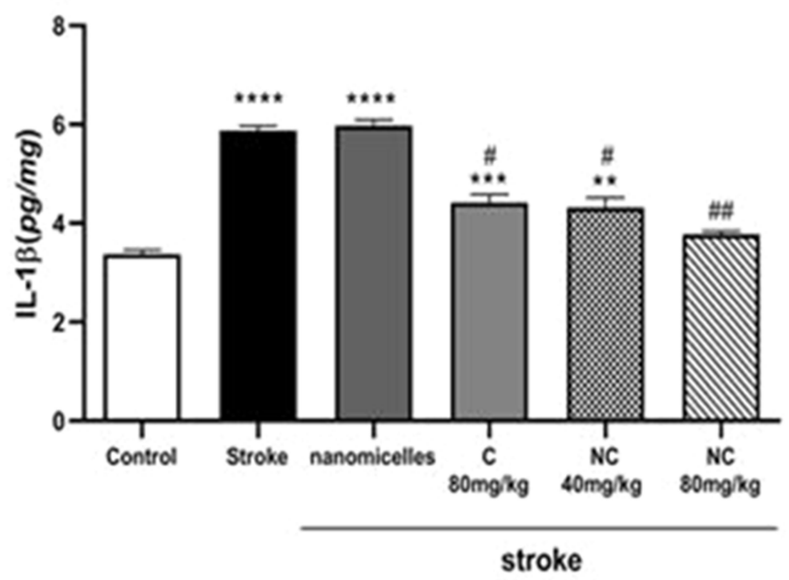

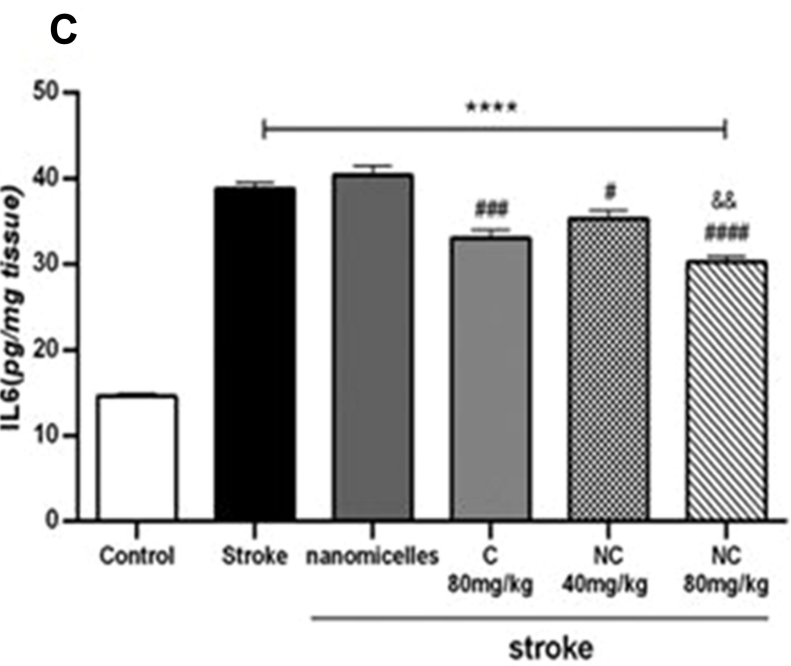

Figure 3 Changes in TNF- $\alpha(\mathbf{A})$, IL-I $\beta(\mathbf{B})$, and IL-6 (C) levels in cerebral ischemia rats administered with NC and C by gavage for I4 days before induction of BCCAO (n $=6)$. ${ }^{* * * *} \mathrm{p}<0.000 \mathrm{I},{ }^{* * *} \mathrm{p}<0.00 \mathrm{I},{ }^{* *} \mathrm{p}<0.01 .{ }^{\$ \$} \mathrm{P}<0.01$. ${ }^{\#}$ and ${ }^{\# \#}$ showed significant differences at $\mathrm{p}<0.05$ and $\mathrm{p}<0.0 \mathrm{I}$ probability level, respectively between the pre-treated stroke rats group with $80 \mathrm{mg} / \mathrm{kg}$ nanomicelle curcumin compared with the stroke group.

seen in rats with cerebral $\mathrm{I} / \mathrm{R}$ injury in stroke. However, the inhibitory effect of $\mathrm{NC}$ on the expression of this protein was evident and downregulation in the expression of NF-kB protein was observed in pre-treated rats with $\mathrm{NC}$ at the dose of $80 \mathrm{mg} / \mathrm{kg}$, and this effect was more severe than in pre-treated rats with free $\mathrm{C}$ (Figure 4). Thus, the anti-inflammatory effects of the $\mathrm{NC}$ formulation may be due to the reduced expression of the NF-KB protein.

\section{Effects of NC on Lipid Peroxidation in Ischemic Brains}

Lipid peroxidation was significantly increased in rats with cerebral ischemia, indicating severe damage to brain cell membranes. However, NC $80 \mathrm{mg} / \mathrm{kg}$ decreased MDA production significantly, indicating the inhibitory effects of
$\mathrm{NC}$ on lipid peroxidation (Figure 5). It appears that the nanomicelle formulation of $\mathrm{C}$ has a strong lipid peroxidation inhibition effect compared to free ones.

\section{Results of Histopathological Study of the Brain}

Pathological examination of the brain in rats with cerebral ischemia showed that neuronal damage and vasculature in the cerebral cortex tissue have occurred to a large extent and pyknotic and necrotic neurons were also seen. However, neuronal damage and degeneration occurred less frequently in the brains of rats pre-treated with $\mathrm{NC}$ as well as free C. Decreased neuronal degradation was more evident in rats pre-treated with $80 \mathrm{mg} / \mathrm{kg} \mathrm{NC}$, indicating the protective effects of $\mathrm{C}$ in cerebral ischemia (Figure 6). 
pNF-KB

$\beta$-Actin

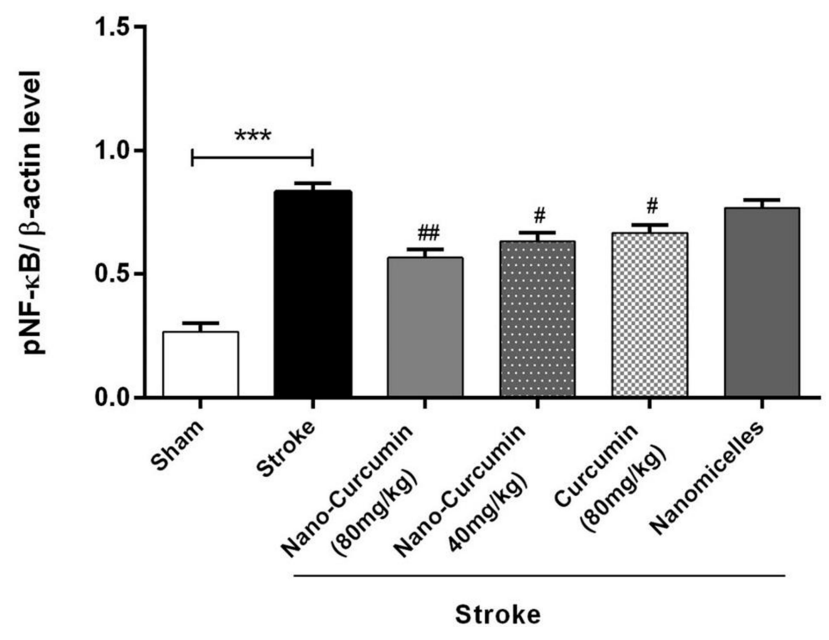

Figure 4 Changes in NF-KB expression levels in rats treated with $\mathrm{NC}$ and $\mathrm{C}(\mathrm{n}=6)$. **** $p<0.001$. \#\# and \# showed significant differences at $p<0.01$ and $p<0.05$ probability levels, respectively, between the pre-treated stroke rats' group with NC and $80 \mathrm{mg} / \mathrm{kg} \mathrm{C}$ compared with the stroke group $(\mathrm{n}=6)$.

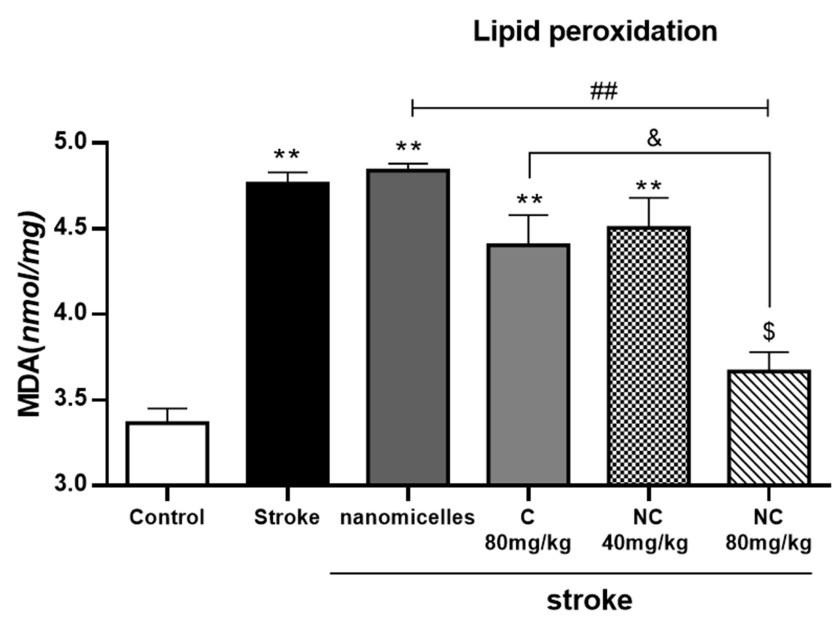

Figure 5 Malondialdehyde (MDA) production in cerebral ischemia rats treated with $N C$ and $C(n=6) .{ }^{*} p<0.01=$ significant difference compared with the control group; \#\# <0. 01 = significant difference compared with stroke group; \&p $<0.05=$ significant difference between the pretreatment groups with $80 \mathrm{mg} / \mathrm{kg} \mathrm{NC}$ compared with $80 \mathrm{mg} / \mathrm{kg} \mathrm{C}$;. $\$ \mathrm{p}<0.05=$ significant differences between the pretreatment groups with $80 \mathrm{mg} / \mathrm{kg} \mathrm{NC}$ compared to the group receiving $40 \mathrm{mg} / \mathrm{kg}$ NC $(n=6)$.

\section{Discussion}

The present study showed a positive effect of triblock copolymer nanomicelles loaded with curcumin on reducing cerebral ischemia/reperfusion injury due to antiinflammatory effects, and these effects were due to the downregulation of cytokine levels involved in the inflammatory signal transduction pathway including Il-1 $\beta$, IL-6,
TNF- $\alpha$, and NF-KB. Reduction of lipid peroxidation was also observed with the administration of $\mathrm{NC}$, which indicates a reduction in damage to neuronal cell membranes.

Curcumin is a compound with antioxidant and antiinflammatory properties. ${ }^{28}$ However, its bioavailability and limited distribution in tissues ${ }^{29}$ have made its clinical application very limited.

The fine morphology of triblock copolymers can be exploited to provide the stimulated release of drugs/small molecules from polymer nanostructures (22). In the present study, well-defined amphiphilic triblock PLA-PEGPLA copolymers were synthesized. It can be deduced that triblock PLA-PEG-PLA copolymers of polymers resulted in the synthesis of a nanomicelle with spherical-shaped morphology, high biocompatibility, and bioavailability, and sustained drug release. Indeed, the application of PEG and PLA-based copolymers results in unique drug release properties as well as controllable biodegradability, excellent biocompatibility. The presence of PEG on the surface of nanomicelles, in addition to facilitation of water adsorption into the inner part of the matrix and corresponding release of encapsulated drug, results in excellent biocompatibility and inhibits the immune system response and fast elimination of nanomicelles. Also, PLA, as the inner part of the micelle, prevents the permeation of destructive substances of the drug into the micelles.

In the present study, it was shown that the NC form increases $\mathrm{C}$ distribution in plasma and tissues including the brain, kidneys, and heart. It was also shown that $\mathrm{NC}$ improves $\mathrm{C}$ absorption. Studies have shown that solubility, permeability to plasma membranes and intestinal mucosa, and the efflux transporter are important factors that affect the absorption process. It seems that reducing the particle size to the nano scale can increase its adsorption and transfer. $^{30,31}$ Therefore, the increase in plasma NC concentration compared to $\mathrm{C}$ can be attributed to the increased $\mathrm{NC}$ uptake in the intestine. Also, as NC plasma concentration decreased, the $\mathrm{NC}$ content in tissues increased and it was shown that the distribution of $\mathrm{NC}$ in tissues is higher than $\mathrm{C}$. It has been shown that $\mathrm{C}$ can be metabolized in the kidney by the $\beta$-glucuronidase and sulfatase enzymes. ${ }^{32,33}$ Therefore, complete clearance from plasma $72 \mathrm{~h}$ after the last dose of $\mathrm{NC}$ and $\mathrm{C}$ in the present study indicates complete urinary $\mathrm{C}$ and $\mathrm{NC}$ excretion.

Other studies have reported that $\mathrm{C}$ inhibited lipid peroxidation, ${ }^{34}$ NF-KB expression, ${ }^{35}$ TNF- $\alpha$ production, and pro-inflammatory interleukins, ${ }^{36}$ which is in line with the current research findings. Cerebral ischemia through 

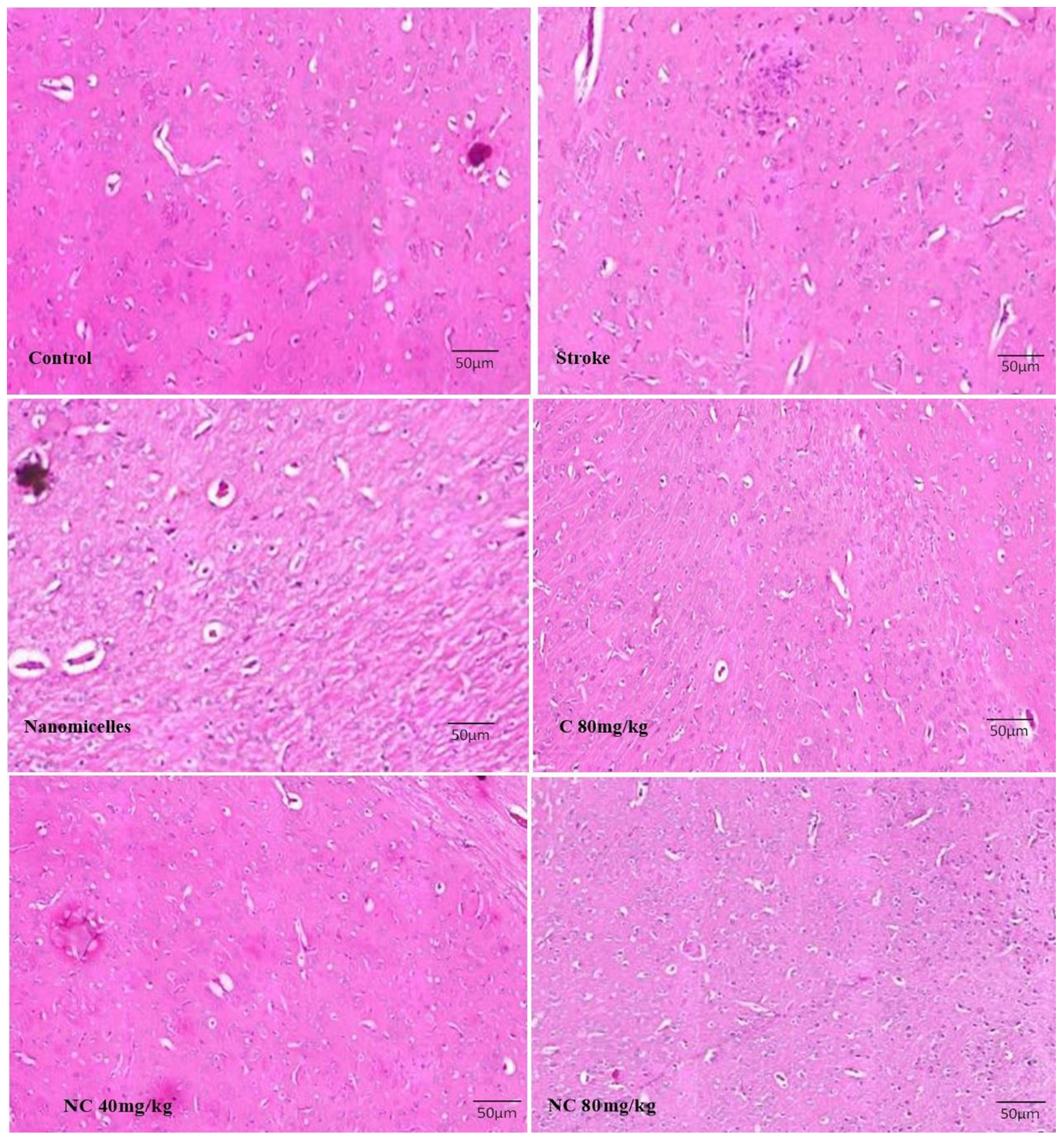

Figure 6 Light microscope images taken from the cross-sections of the hippocampal CAI region (magnification 400x) ( $n=5)$.

oxidative stress and inflammation leads to tissue damage, ${ }^{37}$ and due to the known antioxidant and anti-inflammatory effects of $\mathrm{C}$, it may reduce the rate of tissue damage. Therefore, the reduction in tissue damage due to cerebral $\mathrm{I} /$ $\mathrm{R}$ in rats receiving $\mathrm{NC}$ may be due to the antioxidant and antiinflammatory properties of $\mathrm{C}$. In the present study, downregulation of pro-inflammatory cytokines such as Il-1 $1 \beta$, IL-6, and TNF- $\alpha$ was observed in rats with cerebral I/R injury in stroke, which is consistent with the findings of other studies. ${ }^{38,39}$ However, the results showed that the nanomicelles' formulation of $\mathrm{C}$ in a dose-dependent manner has the ability to downregulate the expression of these proinflammatory cytokines. The inflammatory response after cerebral ischemia has been shown to have severe effects on neurons ${ }^{40}$ and oxidative stress in cerebral ischemia is associated with an inflammatory response. ${ }^{41}$ As noted, ischemic 
brain injury is associated with the accumulation of free radicals that cause severe expression of pro-inflammatory cytokines and worsen oxidative conditions in the brain. ${ }^{42}$ Among these, one of the most important proteins involved in regulating the inflammatory response is NF-KB. The role of this protein in the inflammatory response to ischemic brain injury has been reported ${ }^{43}$ and it has also been noted that NF$\mathrm{KB}$ regulates the expression of inflammatory cytokines such as TNF- $\alpha$, IL- $1 \beta$, and IL- $6 .^{44,45}$ In the present study, an upregulation in NF-KB protein expression and levels of TNF- $\alpha$, IL-1 $\beta$, and IL-6 were observed after cerebral I/R injury in stroke. However, the expression of all these factors involved in downregulation of inflammation in the brains of rats pre-treated with $\mathrm{NC}$ indicates a severe reduction in inflammation due to anti-inflammation effects of NC. TNF$\alpha$ plays an important role in inflammatory diseases by stimulating the production of NF-KB and worsening cerebral I/R injury in stroke ${ }^{46}$ and can increase damage to the blood-brain barrier and cause cerebral edema through vascular permeability augmentation, and increase glutamic acid accumulation. ${ }^{47}$ In the present study, the results of the ELISA assay showed downregulation of TNF- $\alpha$ level pretreated rats by NC. Therefore, it can be concluded that the neuroprotection of $\mathrm{NC}$ is regulated by altering the expression of the NF-KB/TNF- $\alpha$ signaling pathway and thus shows its anti-inflammatory effects.

Oxidative damage in cerebral ischemia has been reported by researchers ${ }^{48,49}$ and it has been stated that the accumulation of free radicals leads to lipid peroxidation. ${ }^{50} \mathrm{MDA}$ is a toxic compound resulting from the peroxidation of plasma membrane lipids that have been used as a sensitive marker for cell damage. ${ }^{51}$ In the present study, levels of MDA were significantly elevated in rats with cerebral $\mathrm{I} / \mathrm{R}$ injury in stroke, but $\mathrm{NC}$ in a dosedependent manner was able to reduce MDA production and prevent its toxicity. Therefore, the reduction of oxidative stress may be part of the protective mechanism of $\mathrm{NC}$ in rats with cerebral $\mathrm{I} / \mathrm{R}$ injury in stroke.

One of the strengths of the present study is the demonstration of the protective effects of $\mathrm{NC}$ on cerebral $\mathrm{I} / \mathrm{R}$ injury. Also, the mechanism of protective effects of $\mathrm{NC}$ on cerebral I/R injury was studied. However, the current study had some limitations. The dose-dependent effects of $\mathrm{NC}$ on cerebral I/R injury require further studies. The present study was performed in vivo, therefore it seems that, in the future, it is necessary to evaluate the effect of $\mathrm{NC}$ on patients with stroke in clinical conditions. More research is needed in this area.

\section{Conclusion}

According to the results obtained in this study, it can be concluded that $\mathrm{NC}$ can play a neuroprotective role in rats with cerebral ischemia/reperfusion injury in stroke through its antioxidant and anti-inflammatory effects. The molecular mechanism of these effects was attributed to the downregulation of expression of the NF-KB signaling pathway. Therefore, $\mathrm{NC}$ can be considered a promising and potential agent for the treatment of cerebral ischemia in the future.

\section{Ethical Approval}

All the experiments were conducted following the guidelines of the Wuhan University of Science and Technology, Wuhan, China and approved by the Animal Ethics Committee.

\section{Acknowledgment}

This study was supported by General Project of Health Commission of Hubei Province (NO.WJ2021M030), and Health Research Project of Metallurgical Safety and Health Branch of Chinese Society of Metals (NO. JKWS02013)

\section{Disclosure}

The authors report no conflicts of interest in this work.

\section{References}

1. Katan M, Luft A. Global burden of stroke. Paper presented at: Seminars in neurology; 2018.

2. Poustchi F, Amani H, Ahmadian Z, et al. Combination therapy of killing diseases by injectable hydrogels: from concept to medical applications. Adv Healthcare Mater. 2021;10(3):2001571. doi:10.10 02/adhm.202001571

3. Khoshnam SE, Winlow W, Farzaneh M, Farbood Y, Moghaddam HF. Pathogenic mechanisms following ischemic stroke. Neurol Sci. 2017;38(7):1167-1186.

4. Zeynalov E, Jones SM, Elliott JP, Borlongan CV. Therapeutic time window for conivaptan treatment against stroke-evoked brain edema and blood-brain barrier disruption in mice. PLoS One. 2017;12(8): e0183985. doi:10.1371/journal.pone.0183985

5. Toyoda K, Koga M, Naganuma M, et al. Routine use of intravenous low-dose recombinant tissue plasminogen activator in Japanese patients: general outcomes and prognostic factors from the SAMURAI register. Stroke. 2009;40(11):3591-3595. doi:10.1161/ STROKEAHA.109.562991

6. Lorenzano S, Vestri A, Bovi P, et al. Thrombolysis in elderly stroke patients in Italy (TESPI) trial and updated meta-analysis of randomized controlled trials. Int J Stroke. 2019:1747493019884525. doi: $10.1177 / 1747493019884525$

7. Eltzschig HK, Collard CD. Vascular ischaemia and reperfusion injury. Br Med Bull. 2004;70(1):71-86. doi:10.1093/bmb/ldh025

8. Amani H, Shahbazi M-A, D'Amico C, Fontana F, Abbaszadeh S, Santos HA. Microneedles for painless transdermal immunotherapeutic applications. J Control Release. 2021;330:185-217. doi:10.1016/j. jconrel.2020.12.019 
9. Huang C, Lu H-F, Chen Y-H, Chen J-C, Chou W-H, Huang H-C. Curcumin, demethoxycurcumin, and bisdemethoxycurcumin induced caspase-dependent and-independent apoptosis via Smad or Akt signaling pathways in HOS cells. BMC Complement Med Ther. 2020;20 (1):1-11. doi:10.1186/s12906-020-2857-1

10. Ashraf K. A comprehensive review on curcuma longa linn.: phytochemical, pharmacological, and molecular study. Int J Green Pharm. 2018;11(4).

11. Abdollahi E, Momtazi AA, Johnston TP, Sahebkar A. Therapeutic effects of curcumin in inflammatory and immune-mediated diseases: a nature-made jack-of-all-trades? J Cell Physiol. 2018;233 (2):830-848. doi:10.1002/jcp.25778

12. Yang G, Yu R, Qiu H, et al. Beneficial effects of emodin and curcumin supplementation on antioxidant defence response, inflammatory response and intestinal barrier of Pengze crucian carp (Carassius auratus var. Pengze). Aquac Nutr. 2020;26 (6):1958-1969. doi:10.1111/anu.13137

13. Abu-Baih RH, Bayoumi A, Ibrahim A, Ewees MG, Abdelraheim SR. Natural polyphenols target the TGF- $\beta$ /caspase-3 signaling pathway in CCl4-induced liver fibrosis in rats. J Adv Biomed Pharm Sci. 2019;2 (4):129-134.

14. Yu J, W-h X, Sun W, Sun Y, Guo Z-L, Yu X-L. Curcumin alleviates the functional gastrointestinal disorders of mice in vivo. J Med Food. 2017;20(12):1176-1183. doi:10.1089/jmf.2017.3964

15. Bhat A, Mahalakshmi AM, Ray B, et al. Benefits of curcumin in brain disorders. BioFactors. 2019;45(5):666-689. doi:10.1002/ biof. 1533

16. Bavarsad K, Riahi MM, Saadat S, Barreto G, Atkin SL, Sahebkar A. Protective effects of curcumin against ischemia-reperfusion injury in the liver. Pharmacol Res. 2019;141:53-62. doi:10.1016/j.phrs.20 18.12 .014

17. Huang L, Chen C, Zhang X, et al. Neuroprotective effect of curcumin against cerebral ischemia-reperfusion via mediating autophagy and inflammation. J Mol Neurosci. 2018;64(1):129-139. doi:10.1007/ s12031-017-1006-X

18. Tsai Y-M, Chien C-F, Lin L-C, Tsai T-H. Curcumin and its nanoformulation: the kinetics of tissue distribution and blood-brain barrier penetration. Int $J$ Pharm. 2011;416(1):331-338. doi:10.1016/j. ijpharm.2011.06.030

19. Anand P, Kunnumakkara AB, Newman RA, Aggarwal BB. Bioavailability of curcumin: problems and promises. Mol Pharm. 2007;4(6):807-818. doi:10.1021/mp700113r

20. Shoba G, Joy D, Joseph T, Rajendran MMR, Srinivas P. Influence of piperine on the pharmacokinetics of curcumin in animals and human volunteers. Planta Med. 1998;64:353-356. doi:10.1055/s-2006957450

21. Cen L, Hutzen B, Ball S, et al. New structural analogues of curcumin exhibit potent growth suppressive activity in human colorectal carcinoma cells. BMC Cancer. 2009;9(1):99. doi:10.1186/1471-2407-9-99

22. Li L, Braiteh FS, Kurzrock R. Liposome-encapsulated curcumin: in vitro and in vivo effects on proliferation, apoptosis, signaling, and angiogenesis. Cancer. 2005;104(6):1322-1331. doi:10.1002/ cncr.21300

23. Maiti K, Mukherjee K, Gantait A, Saha BP, Mukherjee PK. Curcumin-phospholipid complex: preparation, therapeutic evaluation and pharmacokinetic study in rats. Int J Pharm. 2007;330(1-2):155-163. doi:10.1016/j.ijpharm.2006.09.025

24. Rafiee Z, Nejatian M, Daeihamed M, Jafari SM. Application of different nanocarriers for encapsulation of curcumin. Crit Rev Food Sci Nutr. 2019;59(21):3468-3497. doi:10.1080/10408398.2018.149 5174

25. Fan Z, Li J, Liu J, Jiao H, Liu B. Anti-inflammation and joint lubrication dual effects of a novel hyaluronic acid/curcumin nanomicelle improve the efficacy of rheumatoid arthritis therapy. ACS Appl Mater Interfaces. 2018;10(28):23595-23604. doi:10.1021/acsami.8b 06236
26. Ashok B, Arleth L, Hjelm RP, Rubinstein I, Önyüksel H. In vitro characterization of PEGylated phospholipid micelles for improved drug solubilization: effects of PEG chain length and PC incorporation. J Pharm Sci. 2004;93(10):2476-2487. doi:10.1002/ jps. 20150

27. Rao B, Soufir J, Martin M, David G. Lipid peroxidation in human spermatozoa as relatd to midpiece abnormalities and motility. Gamete Res. 1989;24(2):127-134. doi:10.1002/mrd.1120240202

28. Hussain Z, Thu HE, Amjad MW, Hussain F, Ahmed TA, Khan S. Exploring recent developments to improve antioxidant, anti-inflammatory and antimicrobial efficacy of curcumin: a review of new trends and future perspectives. Mater Sci Eng C. 2017;77:1316-1326. doi:10.1016/j.msec.2017.03.226

29. Kunnumakkara AB, Harsha C, Banik K, et al. Is curcumin bioavailability a problem in humans: lessons from clinical trials. Expert Opin Drug Metab Toxicol. 2019;15(9):705-733. doi:10.1080/ 17425255.2019.1650914

30. Li Z, Jiang H, Xu C, Gu L. A review: using nanoparticles to enhance absorption and bioavailability of phenolic phytochemicals. Food Hydrocoll. 2015;43:153-164. doi:10.1016/j. foodhyd.2014.05.010

31. Onoue S, Yamada S, Chan H-K. Nanodrugs: pharmacokinetics and safety. Int J Nanomedicine. 2014;9:1025. doi:10.2147/IJN.S38378

32. Luis PB, Kunihiro AG, Funk JL, Schneider C. Incomplete hydrolysis of curcumin conjugates by $\beta$-glucuronidase: detection of complex conjugates in plasma. Mol Nutr Food Res. 2020;64(6):1901037. doi:10.1002/mnfr.201901037

33. Vareed SK, Kakarala M, Ruffin MT, et al. Pharmacokinetics of curcumin conjugate metabolites in healthy human subjects. Cancer Epidemiol Prev Biomarkers. 2008;17(6):1411-1417. doi:10.1158/ 1055-9965.EPI-07-2693

34. Kim J-H, Jin S, Kwon HJ, Kim BW. Curcumin blocks naproxen-induced gastric antral ulcerations through inhibition of lipid peroxidation and activation of enzymatic scavengers in rats. J Microbiol Biotechnol. 2016;26(8):1392-1397. doi:10.4014/ jmb.1602.02028

35. Xu Y, Liu L. Curcumin alleviates macrophage activation and lung inflammation induced by influenza virus infection through inhibiting the NF-кB signaling pathway. Influenza Other Respi Viruses. 2017;11 (5):457-463. doi:10.1111/irv.12459

36. Wang L, Li N, Lin D, Zang Y. Curcumin protects against hepatic ischemia/ reperfusion induced injury through inhibiting TLR4/NF- $\mathrm{KB}$ pathway. Oncotarget. 2017;8(39):65414. doi:10.18632/oncotarget.18676

37. Guo M, Lu H, Qin J, et al. Biochanin A provides neuroprotection against cerebral ischemia/reperfusion injury by Nrf2-mediated inhibition of oxidative stress and inflammation signaling pathway in rats. Med Sci Monit. 2019;25:8975. doi:10.12659/MSM.918665

38. Wytrykowska A, Prosba-Mackiewicz M, Nyka WM. IL-1 $\beta$, TNF- $\alpha$, and IL-6 levels in gingival fluid and serum of patients with ischemic stroke. J Oral Sci. 2016;58(4):509-513. doi:10.2334/josnusd.16-0278

39. Li Q, Liu Y, Chen L. Effects of PPAR $\gamma$ agonist decreasing the IL-1 $\beta$, IL- 6 and TNF- $\alpha$ content in rats on focal cerebral ischemiareperfusion injury. Biomed Res. 2017;28(21).

40. Sieber MW, Jaenisch N, Brehm M, et al. Attenuated inflammatory response in triggering receptor expressed on myeloid cells 2 (TREM2) knock-out mice following stroke. PLoS One. 2013;8(1): e52982. doi:10.1371/journal.pone.0052982

41. Bai S, Hu Z, Yang Y, et al. Anti-inflammatory and neuroprotective effects of triptolide via the NF- $\kappa$ B signaling pathway in a rat MCAO model. Anat Rec. 2016;299(2):256-266. doi:10.1002/ar.23293

42. Liu H, Wei X, Kong L, et al. NOD2 is involved in the inflammatory response after cerebral ischemia-reperfusion injury and triggers NADPH oxidase 2-derived reactive oxygen species. Int J Biol Sci. 2015;11(5):525. doi:10.7150/ijbs.10927 
43. Lee DH, Lee CS. Flavonoid myricetin inhibits TNF- $\alpha$-stimulated production of inflammatory mediators by suppressing the Akt, mTOR and NF- $\mathrm{BB}$ pathways in human keratinocytes. Eur J Pharmacol. 2016;784:164-172. doi:10.1016/j.ejphar.2016.05.025

44. Maddahi A, Edvinsson L. Cerebral ischemia induces microvascular pro-inflammatory cytokine expression via the MEK/ERK pathway. J Neuroinflammation. 2010;7(1):14. doi:10.1186/1742-2094-7-14

45. Yasuda Y, Shimoda T, Uno K, et al. Temporal and sequential changes of glial cells and cytokine expression during neuronal degeneration after transient global ischemia in rats. $J$ Neuroinflammation. 2011;8 (1):1-10. doi:10.1186/1742-2094-8-70

46. Shih R-H, Wang C-Y, Yang C-M. NF-kappaB signaling pathways in neurological inflammation: a mini review. Front Mol Neurosci. 2015;8:77. doi:10.3389/fnmol.2015.00077

47. Maddahi A, Kruse LS, Chen Q-W, Edvinsson L. The role of tumor necrosis factor- $\alpha$ and TNF- $\alpha$ receptors in cerebral arteries following cerebral ischemia in rat. $J$ Neuroinflammation. 2011;8(1):107. doi:10.1186/1742-2094-8-107
48. Aşcı S, Demirci S, Aşcı H, Doğuç DK, Onaran İ. Neuroprotective effects of pregabalin on cerebral ischemia and reperfusion. Balkan Med J. 2016;33(2):221. doi:10.5152/balkanmedj.2015.15742

49. Ahmed MA, El Morsy EM, Ahmed AA. Pomegranate extract protects against cerebral ischemia/reperfusion injury and preserves brain DNA integrity in rats. Life Sci. 2014;110(2):61-69. doi:10.1016/j. Ifs.2014.06.023

50. Cai J-W, Wu H-X, Jin G-R, Xiang H-B, Lin L. Effect of shuanggenqinnao jianji on SOD MDA of Hippocampus and serum in vascular dementia rats. Chin Arch Tradit Chin Med. 2007;6.

51. Janero DR. Malondialdehyde and thiobarbituric acid-reactivity as diagnostic indices of lipid peroxidation and peroxidative tissue injury. Free Radic Biol Med. 1990;9(6):515-540. doi:10.1016/08915849(90)90131-2
International Journal of Nanomedicine

\section{Publish your work in this journal}

The International Journal of Nanomedicine is an international, peerreviewed journal focusing on the application of nanotechnology in diagnostics, therapeutics, and drug delivery systems throughout the biomedical field. This journal is indexed on PubMed Central, MedLine, CAS, SciSearch ${ }^{\mathbb{}}$, Current Contents ${ }^{\mathbb{R}} /$ Clinical Medicine,
Dovepress

Journal Citation Reports/Science Edition, EMBase, Scopus and the Elsevier Bibliographic databases. The manuscript management system is completely online and includes a very quick and fair peer-review system, which is all easy to use. Visit http://www.dovepress.com/ testimonials.php to read real quotes from published authors. 